\title{
MÁS ALLÁ DEL TEXTO: AUTORES, REDES DE SABER Y FORMACIÓN DE LECTORES
}

por Luz Elena Galván Lafarga, Lucía Martínez Moctezuma y Oresta Lópes PÉREz (coords.). Centro de Investigación y Estudios Superiores en Antropología Social: Universidad Autónoma del Estado de Morelos. Casa Chata: México, 2016. 516 páginas. ISBN 10: 6074863504.

\section{PARA ALÉM DOS MANUAIS ESCOLARES: AUTORES(AS), TEXTOS E CONTEXTOS}

Organizado por Luz Elena Galván Lafarga, Lúcia Martínez Moctezuma e Oresta Lópes Pérez, Más allá del texto: autores, redes de saber y formación de lectores é uma publicação da Casa Chata, Editora do Centro de Investigación y Estudios Superiores en Antropología Social (CIESAS), com sede no México. Publicada em 2016, a obra possui 16 capítulos e está dividido em três partes: a) «Abriendo el siglo: autoras formando mujeres modernas»; b) «Autores formando maestros y ciudadanos lectores»; e, c) «Autores en los territorios de la ciencia y las fronteras ideológicas».

O prólogo intitulado «Más allá de la lógica del autor: tejer textos, construir redes, normalizar ciudadanos» de Agustín Escolano Benito, diretor do Centro Internacional da Cultura Escolar (CEINCE/Espanha), aborda aspectos interessantes ao redor do que chama de manualística, termo cunhado por ele para designar um «sector disciplinario, emergente hace unos años pero ya consolidado, que acogería al conjunto de desarrollos discursivos, análisis genealógicos y observaciones empíricas que se han ido configurando en torno al libro escolar como objeto de conocimiento». ${ }^{1}$ Além disso, destaca dois elementos, que no seu entendimento, estão

\footnotetext{
${ }^{1}$ Escolano, Agustín Benito, «El libro escolar y la cultura de la educación. La manualística, un campo en construcción». In: Currículum editado y sociedad del conocimiento: texto, multimedialidad y cultura de la escuela, ed. Agustín Escolano Benito (Valencia: Tirant lo Blanch, 2006), 13-34.
} 
presentes na obra: «textos primários como uma arte de tecer» e «redes de produção intelectual e de circulação dos textos» (p. 19-20). Enquanto o primeiro serve de metáfora para abordar a trama de textos e contextos por quais passam a produção dos livros escolares, o segundo é referente aos agentes com quais se inter-relacionam tal produção, ou seja, tanto aqueles que produzem quanto aos que se utilizam dos textos para ensinar ou aprender. Destaca ainda, aspectos epistemológicos e metodológicos referentes ao estudo dos manuais escolares, temática em que na Espanha, é um dos principais representantes.

Logo na introdução, levada a cabo pelas organizadoras do livro, destacam-se três elementos: a) localização temática, histórica e geográfica do livro; b) conceitualização do que se entende por «libro de texto»; e, c) apresentação geral das partes e capítulos que compõem o volume. Ressalta-se que o livro é resultado de alguns trabalhos apresentados no Seminário sobre livros de texto organizado pelo Centro de Investigaciones y Estudios Superiores en Antropología Social (CIESAS), e que nessa edição, também contou com a participação de pesquisadores (as) da Espanha e da Bélgica.

Como bem lembrado por alguns autores, ${ }^{2}$ que ainda não há um consenso entre os pesquisadores sobre o conceito de "Manuais Escolares», ainda mais quando se trata de uma obra com colaboração internacional. Nesse sentido, as organizadoras fazem questão de apontar, logo na apresentação, a seguinte questão:

Conservamos todos los términos que definen nuestro objeto de estudio porque, si bien hemos adoptado en nuestras reuniones académicas el término «libro de texto» para distinguir un producto elaborado, específicamente, para la población escolar, dictaminado por un grupo de académicos, ilustrado y puesto en circulación por una casa editorial, aún no existe para Iberoamérica un acuerdo general. La historiografía de la educación española, por ejemplo, ha preferido el uso del término «manual escolar» para distinguirlo de los libros universitarios, sobre los que no pesan controles y restricciones, como sí ocurre en los li-

\footnotetext{
${ }^{2}$ Magalhães, Justino, O mural do tempo: manuais escolares em Portugal. Instituto de Educação da Universidade de Lisboa (Lisboa: Edições Colibri, 2011). Munakata, Kazumi, «O livro escolar como indício da cultura escolar», Revista de História da Educação, ASPHE, 20 (50), (2016): 119-138.
} 
bros destinados a niños y adolescentes. Finalmente, a partir del uso de los tres sustantivos: libro, texto y manual, seguidos o no del adjetivo escolar, en esta publicación se usarán términos como: libro, texto y manual escolar. ${ }^{3}$

Diante das diversas nomenclaturas possíveis, as autoras optam por adotar os diversos sinônimos (livro, texto e manual) para se referirem ao mesmo objeto de estudo. Nesse sentido, a fim de evitar anacronias, nesta resenha também utilizarei «livros de texto e manuais escolares» para designar esse artefato cultural.

Uma das questões mais visíveis na primeira parte do livro é o esforço dos (as) pesquisadores (as) em trazer para o palco da historiografia da educação, o protagonismo das mulheres, seja como professoras e autoras de livros escolares, seja como gestoras e diretoras escolares, ou ainda como editoras de manuais escolares na virada do século XIX e início do xx no México e na Espanha. Uma abordagem histórica das mulheres nesse período requer dos (as) pesquisadores (as) envolvidos um esforço no encontro das fontes e organização dos fatos históricos. Sabe-se que nesse período as mulheres estavam, de forma muito rígida sob as estruturas objetivas da dominação masculina representada pela tríplice força das instituições sociais como a família, a escola e a Igreja. ${ }^{4} \mathrm{E}$, nesse sentido, suas funções, e em muitos casos ambições profissionais eram mutiladas por tais instituições que além de normatizarem e ditarem as regras do que era ou não permitido, também estavam a todo momento na vigilância de suas ações e condutas.

Pioneiras e visionárias, essas mulheres assumiram funções que naquele momento pertenciam majoritariamente ao universo masculino. Assim, podemos verificar no artigo tratado por María del Mar del Pozo Andrés, acerca dos esforços editoriais de Justa Freire em publicar a obra

\footnotetext{
${ }^{3}$ Gabriela Ossenbach y Miguel Somoza, «Introducción», en Los manuales escolares como fuente para la historia de la educación en América Latina, coords, Gabriela Ossenbach y Miguel Somoza (Madrid: Universidad Nacional de Educación a Distancia, 2001), 13-34. Tomado de Luz Elena Galván, Lucía Moctezuma, Martínez, Oresta Lópes Pérez. (coords.), Más allá del texto: autores, redes de saber y formación de lectores. Centro de Investigación y Estudios Superiores en Antropología Social: (México: Universidad Autónoma del Estado de Morelos, Casa Chata, 2016), 30.

${ }^{4}$ Bourdieu, Pierre, A dominação masculina (Rio de Janeiro: Bertrand Brasil, 2014), 12. ed. Tradução de Maria Helena Kühner.
} 
de Ángel Llorca nos anos 1950 no México. Além de editora, Justa Freire também exerceu papel relevante na introdução de métodos da Escola Nova na Espanha antes da ditadura Franquista. Assim como Justa Freire, a professora Delfina Rodrígues, também merece destaque, talvez das autoras tratadas nessa primeira parte da obra, ela seja a que se esforçou para alcançar o posto de professora primária. Não só porque sofria de diversas enfermidades no decorrer da sua trajetória docente, mas também porque era advinda de uma classe economicamente desprivilegiada. Apesar dos poucos recursos, Delfina Rodrígues, conseguiu publicar dois manuais escolares, dos quais um teve significativa circulação nas escolas mexicanas no início do século Xx.

Ainda sobre a docência primária no início do século XX no cenário mexicano, podemos citar o trabalho de Oresta Lópes Pérez, que investigou a trajetória de Elodia Romo, professora primária, que após o falecimento de seu marido, buscou conciliar o cuidado dos filhos com o magistério. Além disso, Elodia Romo, esteve na rede de escritoras de jornais feministas da época. Reivindicava seu direito a exercer a profissão do magistério e aos diretos sociais mais amplos advindos com o surgimento da modernidade.

Por outro lado, temos a história de María Enriqueta Camarillo, pesquisada por Gerardo Antonio Galindo Pelaéz, em que retrata a biografia e os laços familiares dessa professora que foi escritora de um livro basilar para o ensino da literatura nas escolas primárias mexicanas: «Rosas de la infancia», reimpresso mais de oito vezes. Advinda de uma família de Veracruz, com capital cultural e social, Maria Enriqueta casou com o historiador Carlos Pereyra, e possivelmente os diversos capitais (cultural, social, econômico), ${ }^{5}$ fizeram com que conseguisse alcançar espaço no campo editorial naquele momento no México.

\footnotetext{
${ }^{5}$ Capital social para Bourdieu são as redes de relações pessoais e institucionais. Para esse autor, assim como o capital econômico, esta espécie de capital pode ser acumulada, transmitida, reproduzida e convertida ou transmutada em outras espécies de capital. («El sociólogo cuestionado». In: Pierre Bourdieu, Cuestiones de Sociología (Madrid: Akal, 2013), 38-60. Trad. de Enrique Martín Criado). Por sua vez, o capital cultural o capital cultural, para Bourdieu (A dominação masculina, 74) pode existir sob três formas, no estado incorporado, no estado objetivado e no estado institucionalizado. $\mathrm{O}$ estado incorporado remete a socialização primária, quando no interior da família o indivíduo recebe a incorporação de determinadas maneiras de se comportar, de adquirir gostos e uma percepção de mundo que está estritamente ligada as condições materiais e econômicas dessa família. O estado objetivado do capital cultural é a aquisição de recursos materiais como: coleções de quadros, pinturas, ou aquisição de tecnologias. No entanto, é preciso ter capital econômico para adquiri-los e ter o esta-
} 
Para fechar essa primeira parte, Rosa María Hernándes Ramíres e Graciela Isabel Badía Muños abordam a biografia de Elena Cárdenas e seu método de taquigrafia, utilizado na formação profissional de moças, futuras secretárias. Enquanto docente do Instituto Científico y Literário «Porfirio Días» Elena Cárdenas exerceu o magistério por muitos anos e é onde desenvolveu «el Método moderno de fonografia española», mais conhecido posteriormente como Taquigrafía Cárdenas. Além da descrição do método, as autoras também abordam trajetória dessa professora e escritora visionária, que seria reconhecida internacionalmente por seu método avançado de taquigrafia.

A riqueza desta primeira parte, certamente vai além da descrição biográfica, social, política e cultural em que essas mulheres (autoras, escritoras, professoras, etc) estiveram envoltas, mas é uma oportunidade de lançarmos um olhar para as transformações em que a subjetividade feminina era acometida por transformações, não somente pelo ingresso dessas mulheres em ofícios até então ocupado pelos homens, mas também pela luta e resistência delas nos postos aos quais ocuparam. Em certo sentido, todas foram pioneiras «(in)conscientemente» no processo de empoderamento das mulheres, que em pleno século XXI ainda é motivo de muito debate nas Ciências Sociais.

A segunda parte do obra é enriquecida com as biografias de escritores e autores de manuais escolares da Espanha e do México. Julio Ruiz Berrio, traz para o debate a vida e obra de Pablo Montesino, autor do primeiro manual pedagógico produzido na Espanha em 1840. Intitulado «Manual para los maestros de escuelas de párvulos». O estudo de Julio Ruiz Berrio, acerca de Montesino, não se ocupará somente deste fato, ao ir mais além, evidenciando os aspectos pessoais e da vida pública desse autor que também exerceu distintas funções na vida pública, como deputado, médico e professor.

do incorporado do capital cultural para usufruir de suas significações. «É preciso não esquecer, que ele só existe e subsiste como capital ativo e atuante, de forma material e simbólica, na condição de ser apropriado pelos agentes e utilizada como arma e objeto das lutas que se travam nos campos da produção cultural» (Escritos da educação (Petrópolis: Vozes, 2007), 78, 9. ${ }^{a}$ ed. Seleção, organização, introdução e notas de Maria Alice Nogueira e Afrânio Catani. Por fim, o estado institucionalizado do capital cultural encontra seu melhor exemplo no certificado escolar que institui certo poder ao seu detentor, poder este que é reconhecido pelo grupo que compartilha das mesmas crenças dentro do campo que estão inseridos. 
Na sequência temos o trabalho de Antón Costa Rico, que aborda as experiências pedagógicas de Freinet. Mais especificamente, o autor faz um relato sobre as inovações pedagógicas dos professores franceses Célestin (1896-1966), e, Élise Freinet (1899-1983), que inspirados pelo movimento da Escola Ativa propuseram desenvolver nas escolas públicas a construção de uma comunidade escolar assentada no trabalho livre e solidário. Além de relatar a história que envolve esse processo pedagógico, Antón Costa Rico, também aborda seu envolvimento com a temática a partir dos ano de 1974, enquanto ainda era estudante universitário. As experiências do método de Freinet em outros países como no México, e a comunicação entre os alunos de diversos outros países, inspirados por Freinet, também é tema tratado no artigo.

Por sua vez, María Guadalupe García Alcaraz, lança um olhar sobre a obra de Manuel López Cotilla, durante o período de 1834-1859 no México, e avança da discussão sobre as diversas facetas com quais se relacionam o autor e a autoria. Por meio do estudo de diversos trabalhos desenvolvidos por Manuel Cotilla, desde livros de texto, até manuais especializados. Em relação a função social de escritor/autor a pesquisadora localiza três posicionamentos: o primeiro é em relação a quem escreve o documento que se produz institucionalmente; segundo é referente ao produto em que Manuel Cotilla se assume enquanto autor, se trata de escritos com maior rigor analítico e onde o autor se destaca apresentando dados, comparando e buscando alternativas; e por fim, os materiais para professores e estudantes, que são textos compostos a partir de fragmentos de outros, processo em que a autoria original do texto se perde. $\mathrm{O}$ texto é interessante para percebermos as múltiplas facetas entre autor e autoria. Além disso, a autora genuinamente traz para a cena o contexto político, social e cultural, tentando compreender os processos sociais, que fizeram com que esse autor, em alguns casos assinasse suas obra e em outros casos não.

O quarto artigo desta segunda parte é de Blanca García Gutiérrez, que aborda as «Lecciones de Historia Patria» livro utilizado nas escolas mexicanas para o ensino de história, de autoria de Guillermo Prieto (1818-1897), escritor de manuais escolares, jornalista e político. Para Blanca García, nos livros «Memorias de mis tiempos» e "Licciones de Historia patria» estão presentes as diferentes etapas da história desse 
país. A autora busca destacar a biografia desse autor, retratando com os aspectos políticos e sociais, com que ele está presente.

Igualmente, nesta linha biográfica e de contexto de produção bibliográfica voltada ao ensino escolar, destaca-se o trabalho de Irma Leticia Moreno Gutiérrez, que aborda a vida e obra de Enrique Conrado Rébseamen Egloff (1857-1904), professor suíço que emigrou para o México durante as últimas décadas do século XIX e fez carreira como educador e precursor de metodologias educativas. Irma Gutiérrez busca analisar dois livros escolares do autor: "Método de escritura-lectura o sea enseñanza de la lectura por medio de la escritura con aplicación del fonetismo y la marcha analítico-sintética» de 1889, voltado para ensino de crianças e «La enseñanza de la escritura y lectura. Guía metodológico» de 1899, voltado para os professores e estudantes da escola normal. Para a autora, Enrique Egloff, foi um dos educadores estrangeiros do século Xx, mais reconhecidos no México. A herança cultural de suas ideias em torno da profissionalização dos professores e do papel protagonista que as escolas normais tiveram como espaços de formação científico-pedagógico é um dos legados desse personagem da história da educação naquele país.

Para finalizar esta segunda parte, temos o trabalho de Lucía Martínez Moctezuma, que aborda a vida e obra de Lúcio Tapia, responsável no México, pela tradução e adaptação do livro «Le Tour de la France» escrito por Augustine Fouilleé, também conhecida pelo pseudônimo de G. de Brune. Esse livro alcançou diversas traduções em vários países, sendo que no México Lucio Tapia fez uma adaptação da obra para o ensino infantil. O manual escolar e seu contexto de tradução e adaptação é abordado neste trabalho, que além da biografia do autor em questão, também aborda os aspectos editoriais, econômicos e educacionais dessa obra no México.

Tal como nos trabalhos apresentados na primeira parte, esta segunda seção destaca os valores morais religiosas, nacionalistas e de identidade nacional contido nos manuais escolares do século XIX e início do XX. Mas também vai além, pois busca conhecer a trajetória de cada um desses autores, que reunidos nos possibilita lançar luz sobre a história intelectual ibero americana que marcou esse período. Nesta rede de biografias, os aspectos políticos, culturais, e educacionais são postos em relevo, possi- 
bilitando análises mais amplas, sobre a vida intelectual ibero americana, marcada pelo intercâmbio de ideias, teorias e metodologias de ensino.

A terceira e última parte da obra, aborda o contexto mais amplo de produção de manuais escolares na Espanha, Bélgica e Congo. Doravante, avança na discussão metodológica, pois traz o contexto de recepção e de análise de uma área ainda pouco pesquisa, a das Ciências exatas.

Assim, Federico Lazarán Miranda, no capítulo sobre «Salvador Mosqueira Roldán y el libro de Física General» apresenta três eixos analíticos com o objetivo de explicar a função desse autor na produção de livros de Física, durante o século xx no México. O primeiro eixo gira em torno do próprio autor e apresenta a forma em que se desenvolve a tradição de engenheiros precursores de ciências exatas naquele país. O segundo eixo sintetiza as redes profissionais e científicas que teve Mosqueira com outros personagens importantes como Manual Sandoval Vallarta, Carlos Grael Fernández e Nabor Carrillo. O último versa sobre o texto denominado «Física General para la enseñanza preparatoria y vocacional», obra em dois tomos publicada em 1934 e com sua vigésima edição em 1992.

Por sua vez, Robert Barbry, Franck Simon e Marc Depaepe trazem para o debate o texto intitulado «Même absent, il était présent»: Hilaire Delobel (1889-1959) como autor de manuales escolares. Tratam o caso do inspetor e professor católico belga que nasceu no final do século XIX, na cidade de Ypres, oeste de Bélgica. Combinando seu fervor católico com sua formação de inspetor, foi a pessoa indicada como autor de artigos e livros escolares. Também se dedicou a publicação de artigos em revistas pedagógicas, livros e folhetos e manuais escolares. Entre suas primeiras publicações, conta a partir de 1924, os 10 cadernos de caligrafía editados em Neerlandés e em francês. Também publicou manuais de geografia, história e de sua obra mais importante «Knap en Klaar» (Inteligente y claro), curso de aritmética em dez partes editada por Van In a Lier, que será reeditada até 1960. Para os autores, «Knap en Klaar», foi um dos manuais mais conhecidos na Bélgica, desde sua publicação nos anos trinta até depois da II Guerra Mundial em 1960.

Na sequência temos o texto sobre "Gustaaf Hulstaert (1900-1990), autor de manuales escolares en el Congo: pioneiro paradójico y controversial» de Honoré Vinck, Frank Simon e Marc Depaepe. O objetivo deste 
trabalho é situar o papel desse autor, missionário do Sagrado Coração no Congo, como autor de manuais escolares. Para os autores, Hulstaert estava convencido de que o ensino, como eixo central da cristianização do indígena deveria fundar-se na cultura Bantú. Como missionário, buscava saber mais para aprofundar seus conhecimentos em diferentes campos da cultura, filosofia, política, e psicologia. Muito cedo, começou a criar uma concepção sobre a responsabilidade cultural do missionário e do colonizador. Seu compromisso foi claro, o respeito total e absoluto da língua e cultura dos povos locais, que chamará, desde então «indigénisme», palavra que caracterizará, nas seguintes décadas, sua atitude prática e ideológica, em oposição a assimilação que busca destruir a cultura Bantú para ser substituída pela cultura ocidental. Se por um lado, os livros de Hulstaert estão fortemente vinculados a questão da valorização da cultura Congolesa e do nacionalismo Mongo na tentativa de dar aos congoleses confiança neles mesmos e suplantar o apreço por sua cultura e história. Por outra, parte de seus livros defendem a submissão frente às autoridades eclesiásticas, neste sentido não se distancia da doutrina ensinada nas escolas católicas ocidentais.

O último trabalho apresentado no livro é de Ana Badanelli, Kira Mahamud y Miguel Somoza Rodrígues, e tem como objetivo analisar a vida e obra de Agustín Serrano de Haro, professor, inspetor e autor de textos escolares durante o franquismo. Autor de vários manuais para o ensino durante o período do Regime ditatorial de Franco, esse autor terá sucesso editorial, visto que vários de seus livros se tornaram verdadeiros best sellers escolares. Nesse sentido, os pesquisadores buscam conhecer as causas e motivos desse sucesso editorial, bem como aprofundar o estudo por meio da biografia pessoal, profissional e social deste autor que por meio dos seus escritos representar as bases católicas e nacionalistas de amor a pátria e a Igreja nesse período da história da educação espanhola.

Por fim, gostaria de salientar que as pesquisas apresentadas nessa obra são relevantes para a história da educação e de forma mais específica para aqueles interessados no estudo dos manuais escolares. Isto porque estes trabalhos, apresentam os contextos de produção e as redes de saber que permeavam a constituição de um campo educacional entre os séculos XIX e XX, momento em que para esses países a escolarização 
da população era uma pauta das elites dirigentes, com vista ao alcance da delimitação de um Estado nacional em conformidade com a moral católica. Penso, que a constituição do campo educacional nesses países atrelou-se a questões culturais, políticas e pedagógico-científicas, e consequentemente, a rede de relações pessoais e institucionais entre vários dos autores aqui tratados, pode servir de base para a compreensão desse quadro histórico e sociológico. Nesse sentido, para compreender a produção de manuais escolares, cabe também direcionar o olhar para tais questões, no sentido de que sem conhecer o contexto, bem como os produtores, dificilmente se compreende os manuais escolares, sua complexidade e riqueza como fonte de pesquisa para a história da educação.

Marcelo Cigales Universidade Federal de Santa Catarina (Brasil) marcelo.cigales@gmail.com 